\title{
Effects of fertilizers used in agricultural fields on algal blooms
}

\author{
Chakraborty, Subhendu; Tiwari, P. K.; Sasmal, S. K.; Misra, A. K.; Chattopadhyay, Joydev
}

Published in:

European Physical Journal: Special Topics

Link to article, DOI:

10.1140/epjst/e2017-70031-7

Publication date:

2017

Document Version

Early version, also known as pre-print

Link back to DTU Orbit

Citation $(A P A)$ :

Chakraborty, S., Tiwari, P. K., Sasmal, S. K., Misra, A. K., \& Chattopadhyay, J. (2017). Effects of fertilizers used in agricultural fields on algal blooms. European Physical Journal: Special Topics, 226(9), 2119-2133. https://doi.org/10.1140/epjst/e2017-70031-7

\section{General rights}

Copyright and moral rights for the publications made accessible in the public portal are retained by the authors and/or other copyright owners and it is a condition of accessing publications that users recognise and abide by the legal requirements associated with these rights.

- Users may download and print one copy of any publication from the public portal for the purpose of private study or research.

- You may not further distribute the material or use it for any profit-making activity or commercial gain

- You may freely distribute the URL identifying the publication in the public portal 


\title{
Effects of fertilizers used in agricultural fields on algal blooms
}

\author{
Subhendu Chakraborty ${ }^{1, a}$, P.K. Tiwari ${ }^{2}$, S.K. Sasmal ${ }^{2}$, A.K. Misra ${ }^{3}$, and Joydev \\ Chattopadhyay $^{2}$ \\ 1 VKR Centre for Ocean Life, National Institute of Aquatic Resources, Technical University \\ of Denmark, Charlottenlund Slot, Jgersborg Allé, DK-2920 Charlottenlund, Denmark \\ 2 Agricultural and Ecological Research Unit, Indian Statistical Institute, Kolkata, West \\ Bengal 700108, India \\ 3 Department of Mathematics, Institute of Science, Banaras Hindu University, Varanasi, \\ Uttar Pradesh 221005, India
}

\begin{abstract}
The increasing occurrence of algal blooms and their negative ecological impacts have led to intensified monitoring activities. This needs the proper identification of the most responsible factor/factors for the bloom formation. However, in natural systems, algal blooms result from a combination of factors and from observation it is difficult to identify the most important one. In the present paper, using a mathematical model we compare the effects of three human induced factors (fertilizer input in agricultural field, eutrophication due to other sources than fertilizers, and overfishing) on the bloom dynamics and DO level. By applying a sophisticated sensitivity analysis technique, we found that the increasing use of fertilizers in agricultural field causes more rapid algal growth and decreases DO level much faster than eutrophication from other sources and overfishing. We also look at the mechanisms how fertilizer input rate affects the algal bloom dynamics and DO level. The model can be helpful for the policy makers in determining the influential factors responsible for the bloom formation.
\end{abstract}

\section{Introduction}

Farmers frequently use fertilizers to obtain high yield where fertilizers contain basic materials: nitrogen, potassium, phosphorus and other nutrients, like zinc, needed for healthy plant growth [1]. To increase agricultural productivity, both developed and developing nations are using increasing doses of fertilizers. Only a fraction of the fertilizers is utilized by the crop and the remainder accumulates in the soil or lost as runoff. Such excess use of fertilizers is not at all healthy for the rest of the environment [2]. Some of the chemical fertilizers are known to cause gastric cancer, goitre, birth malformations, hypertension, testicular cancer, stomach cancer, Blue Baby Syndrome, etc. Apart from these direct effects, there are also several other adverse effects of excess use of fertilizers. High amount of fertilizers can find their way into waterways, causing an excess of algae and resulting in loss of dissolved oxygen (DO) in the water

\footnotetext{
a e-mail: subc@aqua.dtu.dk
} 
column [3]. This has a negative effect on fish and other aquatic populations. In recent days, agricultural run-off is considered as one of the largest causal pollution problems globally [4]. Thus, it is important to investigate the mechanisms of potential harmful effects of fertilizers on algal blooms.

Mathematical modeling of water pollution dynamics is a mature subject in theoretical ecology and water quality research [5-7]. Many of these studies have been directed to eutrophication and to understand the interplay between algal biomass and nutrient supply. A general theoretical approach for the interpretation of bloom development has been proposed using the theory of excitable media [8,9]. Later on, Truscott [10] used this theory to explain the development of sudden phytoplankton peaks as a consequence of variations of the micro-algal growth rates above a critical value. Although, there are several factors found to be responsible for initiating bloom dynamics by affecting growth rate $[11,12]$, nutrient remains the most important one [13]. Some of the studies showed that simultaneous reductions of different nutrient sources are required for effective long-term control and management of algal blooms $[14,15]$. Some mathematical models are also available in the literature where the effects of excessive inflow of nutrients from agricultural fields on the occurrence of algal blooms are investigated [16-23]. These studies showed that algal population growth highly depends on nutrient discharge. A recent study of Misra et al. [19] suggested that farmers should restrict the use of the amount of fertilizers in order to reduce eutrophication and the awareness among farmers plays an important role in controlling algal blooms.

In most of the previous modelling studies, it is considered that the nutrients are coming to the water bodies through the agricultural runoff $[18,19,23]$. However, in the real situation, the amount of nutrients through runoff to the water bodies depends on the amount of fertilizers used to increase the agricultural yields. It is well known that the nutrients in the water bodies are also formed from the detritus and in fact the amount of detritus does not only depend on dead part of algae but also depends on the residual of the crops in the agricultural fields where the residuals reach to the water bodies through runoff and increase the amount of detritus in the water. As soon as the amount of detritus in the water body increases, the concentration of nutrients in the water body increases as nutrients are regenerated from detritus. Although, these interrelated factors significantly affect the whole aquatic ecosystem, especially eutrophication, algal blooms, depletion of DO, survival of aquatic population, etc., to the best of our knowledge, the effect of fertilizers have never been considered explicitly in modeling eutrophication and algal blooms. Thus, in the present paper, our main aim is to study the role of fertilizer input rate on different dynamical behavior of the system and also how it develops harmful algal blooms (HABs). Although, HABs can occur in two different ways: (1) through the depletion of DO in the water column and (2) by releasing toxic chemicals, here we mainly concentrate on the first case. We also use a sensitivity analysis technique to compare between the effects of different factors on the bloom formation and how it is helpful in identifying the most influential factor responsible for the bloom formation.

\section{Mathematical model}

Let $F(\mathrm{~kg} / \mathrm{ha})$ be the concentration of fertilizers and $A$ (ton $/$ ha) be the agricultural production. Furthermore, let $N(\mu \mathrm{gN} / \mathrm{l}), P(\mu \mathrm{gN} / \mathrm{l}), S(\mu \mathrm{gN} / \mathrm{l})$ and $C(\mathrm{mg} / \mathrm{l})$ be the amount of nutrients (nitrogen in our case), density of algae, density of detritus and concentration of DO, respectively. It is assumed that fertilizers are spread in the farms with a constant rate. Some of the fertilizers deplete naturally while some of them are used up to increase the agricultural production. Fertilizer increases the 
agricultural production up to a certain limit and a large amount of fertilizer does not increase the production in the same proportion. Therefore, the depletion rate of fertilizers used up to increase in agricultural production is assumed to be followed by Holling type II interaction between the concentration of fertilizers and agricultural production. However, in the absence of fertilizers, agricultural production increases following logistic growth law depending on the natural nutrients available in the field.

Further, it is considered that nutrients are coming to the system through agricultural runoff as well as sources other than agriculture. There is a natural depletion of nutrients in the lake and nutrients are also taken by algae for their growth. There is a natural death of algae and algae also die due to higher predation. Detritus are formed due to the death of algal population and runoff of the crop residual. Detritus are being decomposed by the bacterial population to form nutrients. Nutrient regenerations by bacterial populations are taken into account without explicitly considering equations for bacterial populations. Decompositions due to both anaerobic and aerobic bacteria are considered. Anaerobic bacteria does not need oxygen to decompose detritus to form nutrients whereas the decomposition process by aerobic bacteria needs a large amount of DO. The inflow of DO in the lake is through water-air interaction and photosynthesis by algae. By considering all of these facts together, we have the following differential equation:

$$
\begin{aligned}
\frac{d F}{d t} & =Q-\alpha_{0} F-\frac{k_{1} F A}{k_{12}+F}, \\
\frac{d A}{d t} & =r A\left(1-\frac{A}{L}\right)+\frac{\lambda_{1} k_{1} F A}{k_{12}+F}, \\
\frac{d N}{d t} & =q+\gamma \alpha Z F-\alpha_{1} N-\frac{\beta_{1} N P}{\beta_{12}+N}+\pi \epsilon S, \\
\frac{d P}{d t} & =\frac{\theta_{1} \beta_{1} N P}{\beta_{12}+N}-\alpha_{2} P-\beta_{10} P^{2}, \\
\frac{d S}{d t} & =\eta \alpha^{\prime} Z A+\pi_{1} \alpha_{2} P+\pi_{2} \beta_{10} P^{2}-\epsilon S, \\
\frac{d C}{d t} & =q_{c}-\alpha_{3} C+\lambda_{11} P-\delta_{2} S C .
\end{aligned}
$$

In the model (1), the constant $Q$ is the rate at which fertilizers are used in the farms and the constant $\alpha_{0}$ is the rate at which fertilizers deplete naturally in the farms. The constant $k_{1}$ is the maximum rate at which fertilizers are depleted due to agricultural production and the constant $k_{12}$ limits this rate. The constants $r$ and $L$ are the intrinsic growth rate and carrying capacity of agricultural production in the absence of fertilizers. The proportionality constant $\lambda_{1}$ stands for the increase in agricultural yield due to application of fertilizers. The parameter $q$ denotes the nutrient input in the aquatic system due to other sources than fertilizer and can be a representative of eutrophication due to other sources. The constant $\gamma$ is the input rate of nutrient in the aquatic system through agricultural runoff, $\alpha$ is the nutrient content per unit of fertilizer, $Z$ is the area of the farmland, $\eta$ is the growth rate of detritus due to runoff of the residual of crops and $\alpha^{\prime}$ is the nutrient content per unit of agricultural production. $\alpha_{1}$ represents the natural depletion rate of nutrient. $\beta_{1}$ is the nutrient uptake rate by algae and $\beta_{12}$ is the half saturation constant of uptake, $\theta_{1}$ is the conversion of nutrient into algal density. $\alpha_{2}$ is the natural mortality of algae whereas $\beta_{10}$ is the algal mortality due to higher predation which can also be a representative of overfishing by larger top predatory fish. $\epsilon$ is the depletion rate of detritus due to the biochemical activity by bacteria. We assume $\epsilon=\delta+\delta_{1} C$, where $\delta$ 
and $\delta_{1}$ are the depletion rates in the absence $(C=0)$ and presence $(C>0)$ of dissolved oxygen, respectively. Depletion of detritus happens due to the biochemical processes for the conversion of detritus to nutrient conducted by anaerobic and aerobic bacteria present in the system. Conversion by anaerobic bacteria does not need DO and thus nutrient regeneration only depends on the amount of detritus present in the lake. On the other hand, aerobic bacteria utilizes oxygen and organic matter to yield energy that increases the remineralization rate of nutrient throughout the degradation of detritus. This process results in the depletion of DO level at a rate $\delta_{2}$. This type of conversion depends on both the amount of detritus present in the lake as well as the concentration of DO in the water column. Thus, in the presence of oxygen both type of bacteria take part into the degradation process whereas only anaerobic bacteria remains active in the absence of oxygen. $q_{c}$ is the inflow rate of DO due to surface re-aeration, $\alpha_{3}$ is the natural depletion rate of nutrient and $\lambda_{11}$ is the inflow rate of DO by unit algal density. All the above constants are assumed to be positive and the constants $\eta, \pi, \pi_{1}, \pi_{2}$ and $\theta_{1}$ lie between 0 and 1 . The biological meanings of all the variables and parameters of the model (1) are summarized in Table 1.

We assume that the dynamics of nutrient is not directly affected by the concentration of DO. Although, when oxygen is depleted, nitrate and nitrite are reduced and transformed to ammonia, but we did not consider such increase in nutrient at low DO level to avoid further complexity of the model.

We analyze the model (1) with the initial conditions, $F(0)>0, A(0) \geq 0, N(0)>$ $0, P(0) \geq 0, S(0) \geq 0, C(0)>0$.

\section{Mathematical analysis}

In this section, we analyze our model (1) mathematically. First, we find all possible equilibria of our model (1) and conditions of their existence.

\subsection{Possible equilibrium points and their existence conditions:}

The model system (1) has the following four non-negative equilibria:

1. The equilibrium point $E_{0}=\left(F_{0}, 0, N_{0}, 0,0, C_{0}\right)$, with $F_{0}=\frac{Q}{\alpha_{0}}, N_{0}=\frac{\gamma \alpha Z Q+q \alpha_{0}}{\alpha_{0} \alpha_{1}}$ and $C_{0}=\frac{q_{c}}{\alpha_{3}}$, when there is no agricultural production as well as no algae and detritus in the system. The equilibrium $E_{0}$ always exists in the system.

2. The equilibrium $E_{1}=\left(F_{1}, A_{1}, N_{1}, 0, S_{1}, C_{1}\right)$, where there is no algae in the system. Here, the densities $F_{1}, A_{1}, N_{1}, S_{1}$, and $C_{1}$ are defined as follows:

$$
A_{1}=\frac{L}{r}\left(r+\frac{\lambda_{1} k_{1} F_{1}}{k_{12}+F_{1}}\right), N_{1}=\frac{q+\pi\left(\delta+\delta_{1} C_{1}\right) S_{1}}{\alpha_{1}}, \quad C_{1}=\frac{q_{c}}{\alpha_{3}+\delta_{2} S_{1}} . F_{1} \text { is a }
$$

positive root of the following equation:

$$
f(F)=\frac{L}{r}\left(r+\frac{\lambda_{1} k_{1} F}{k_{12}+F}\right)-\frac{\left(Q-\alpha_{0} F\right)}{k_{1}} \frac{k_{12}}{F}=0 .
$$

From equation (2), the followings may be easily noted:

$$
\begin{aligned}
& \left(a_{1}\right) \text { when } F \rightarrow 0, f(F) \rightarrow-\infty, \\
& \left(a_{2}\right) f\left(Q / \alpha_{0}\right)>0, \text { and } \\
& \left(a_{3}\right) f^{\prime}(F)>0 \text {, for } F \in\left(0, Q / \alpha_{0}\right) .
\end{aligned}
$$


The above points $\left(a_{1}\right),\left(a_{2}\right)$ and $\left(a_{3}\right)$ together imply that there exists a unique positive real root $F=F_{1}$ of the equation (2) in the interval $\left(0, Q / \alpha_{0}\right)$.

$S_{1}$ is the positive root of the following quadratic:

$$
\delta \delta_{2} S^{2}+\left(\delta \alpha_{3}+q_{c} \delta_{1}-\eta \alpha^{\prime} Z \delta_{2} A_{1}\right) S-\eta \alpha^{\prime} Z \alpha_{3} A_{1}=0 .
$$

Equation (3) has a unique positive root and thus the equilibrium $E_{1}$ always exists in the system.

3. The equilibrium when there is no agricultural production is given by $E_{2}=$ $\left(\frac{Q}{\alpha_{0}}, 0, N_{2}, P_{2}, S_{2}, C_{2}\right)$, where the densities $N_{2}, P_{2}, S_{2}$ and $C_{2}$ are given as follows:

$N_{2}=\frac{\beta_{12}\left(\alpha_{2}+\beta_{10} P_{2}\right)}{\theta_{1} \beta_{1}-\left(\alpha_{2}+\beta_{10} P_{2}\right)}, \quad C_{2}=\frac{q_{c}+\lambda_{11} P_{2}}{\alpha_{3}+\delta_{2} S_{2}}, \quad S_{2}$ is the positive root of the following quadratic equation:

$$
\begin{gathered}
\delta \delta_{2} S^{2}+\left\{\delta \alpha_{3}+\delta_{1}\left(q_{c}+\lambda_{11} P_{2}\right)-\delta_{2}\left(\pi_{1} \alpha_{2} P_{2}+\pi_{2} \beta_{10} P_{2}^{2}\right)\right\} S \\
-\alpha_{3}\left(\pi_{1} \alpha_{2} P_{2}+\pi_{2} \beta_{10} P_{2}^{2}\right)=0
\end{gathered}
$$

and $P_{2}$ is the unique positive root of the following cubic equation

$$
\begin{aligned}
{\left[\tilde{q}+\left(\pi \pi_{1}-\frac{1}{\theta_{1}}\right) \alpha_{2} P+\right.} & \left.\left(\pi \pi_{2}-\frac{1}{\theta_{1}}\right) \beta_{10} P^{2}\right] \\
& {\left[\left(\theta_{1} \beta_{1}-\alpha_{2}\right)-\beta_{10} P\right]-\beta_{12} \alpha_{1}\left(\alpha_{2}+\beta_{10} P\right)=0 . }
\end{aligned}
$$

The equilibrium $E_{2}$ exists if the following condition is satisfied

$$
\left(\theta_{1} \beta_{1}-\alpha_{2}\right) \tilde{q}-\beta_{12} \alpha_{1} \alpha_{2}>0
$$

where $\tilde{q}=q+\frac{\gamma \alpha Z Q}{\alpha_{0}}$.

4. The interior equilibrium where all the six components of our model exist is given by $E^{*}=\left(F^{*}, A^{*}, N^{*}, P^{*}, S^{*}, C^{*}\right)$. The equilibrium $E^{*}$ exists provided the following condition is satisfied

$$
\left(\theta_{1} \beta_{1}-\beta_{12} \alpha_{2}\right) q_{1}-\beta_{12} \alpha_{1} \alpha_{2}>0 .
$$

Note that $F^{*}=F_{1}$ and $A^{*}=A_{1}$. The densities $N^{*}, P^{*}, S^{*}$ and $C^{*}$ may be obtained by solving the following simultaneous algebraic equations:

$$
\begin{aligned}
& 0=q+\gamma \alpha Z F^{*}-\alpha_{1} N-\frac{\beta_{1} N P}{\beta_{12}+N}+\pi\left(\delta+\delta_{1} C\right) S, \\
& 0=\frac{\theta_{1} \beta_{1} N}{\beta_{12}+N}-\alpha_{2}-\beta_{10} P \\
& 0=\eta \alpha^{\prime} Z A^{*}+\pi_{1} \alpha_{2} P+\pi_{2} \beta_{10} P^{2}-\left(\delta+\delta_{1} C\right) S \\
& 0=q_{c}-\alpha_{3} C+\lambda_{11} P-\delta_{2} S C .
\end{aligned}
$$

From equation (10), we have

$$
\left(\delta+\delta_{1} C\right) S=\eta \alpha^{\prime} Z A^{*}+\pi_{1} \alpha_{2} P+\pi_{2} \beta_{10} P^{2} .
$$

From equation (9), we have

$$
N=\frac{\beta_{12}\left(\alpha_{2}+\beta_{10} P\right)}{\theta_{1} \beta_{1}-\left(\alpha_{2}+\beta_{10} P\right)} .
$$


Now, using equations (12) and (13) in equation (8), we have

$$
\begin{array}{r}
g(P)=\left[q_{1}+\left(\pi \pi_{1}-\frac{1}{\theta_{1}}\right) \alpha_{2} P+\left(\pi \pi_{2}-\frac{1}{\theta_{1}}\right) \beta_{10} P^{2}\right] \\
{\left[\left(\theta_{1} \beta_{1}-\alpha_{2}\right)-\beta_{10} P\right]-\beta_{12} \alpha_{1}\left(\alpha_{2}+\beta_{10} P\right)=0,}
\end{array}
$$

where $q_{1}=q+\gamma \alpha Z F^{*}+\pi \eta \alpha^{\prime} Z A^{*}$.

From equation (14), the followings may be easily noted:

$$
\begin{aligned}
& \left(b_{1}\right) g(0)>0 \text { provided }\left(\theta_{1} \beta_{1}-\alpha_{2}\right) q_{1}-\beta_{12} \alpha_{1} \alpha_{2}>0, \\
& \left(b_{2}\right) g(\tilde{P})<0, \text { for } \tilde{P}=\frac{\theta_{1} \beta_{1}-\alpha_{2}}{\beta_{10}} \text { and } \\
& \left(b_{3}\right) g^{\prime}(P)<0, \text { for } P \in(0, \tilde{P}) .
\end{aligned}
$$

The above points $\left(b_{1}\right),\left(b_{2}\right)$ and $\left(b_{3}\right)$ together imply that there exists a unique positive root $P=P^{*}$ of equation $(14)$ in the interval $(0, \tilde{P})$. Using this value of $P=P^{*}$ in equation (13), we get the values of $N=N^{*}$.

From equation (11), we have

$$
C=\frac{q_{c}+\lambda_{11} P^{*}}{\alpha_{3}+\delta_{2} S}
$$

Using equation (15) in equation (12), we have

$$
\begin{gathered}
\delta \delta_{2} S^{2}+\left\{\delta \alpha_{3}+\delta_{1}\left(q_{c}+\lambda_{11} P^{*}\right)-\delta_{2}\left(\eta \alpha^{\prime} Z A^{*}+\pi_{1} \alpha_{2} P^{*}+\pi_{2} \beta_{10} P^{* 2}\right)\right\} S \\
-\alpha_{3}\left(\eta \alpha^{\prime} Z A^{*}+\pi \alpha_{2} P^{*}+\pi_{2} \beta_{10} P^{* 2}\right)=0 .
\end{gathered}
$$

Equation (16) has exactly one positive root, say $S^{*}$. Now, from equation (15), we can get the value of $C^{*}$.

Lemma 1 The region of attraction for all solutions initiating in the positive octant is given by the set $\Omega$ [24]:

$$
\begin{gathered}
\Omega=\left\{(F, A, N, P, S, C): 0 \leq F<\frac{Q}{\alpha_{0}} ; 0 \leq A \leq A_{m} ; 0 \leq N+P+S \leq \frac{\bar{q}}{\delta_{m}}\right. \\
\left.0 \leq C \leq C_{m}\right\}
\end{gathered}
$$

where

$$
\begin{aligned}
& A_{m}=\frac{L}{r}\left(r+\frac{\lambda_{1} k_{1} Q}{k_{12} \alpha_{0}+Q}\right), \bar{q}=q+\frac{\gamma \alpha Z Q}{\alpha_{0}}+\eta \alpha^{\prime} Z A_{m}, \\
& \delta_{m}=\min \left\{\alpha_{1},\left(1-\pi_{1}\right) \alpha_{2},(1-\pi) \delta\right\}, C_{m}=\frac{q_{c} \delta_{m}+\lambda_{11} \bar{q}}{\alpha_{3} \delta_{m}} .
\end{aligned}
$$

\subsection{Stability of equilibria of our model (1):}

Theorem 1 1. The equilibrium $E_{0}$ is always stable in $F, N, S$ and $C$ directions and unstable in $A$ direction. Further, it is unstable (or stable) in $P$ direction whenever the equilibrium $E_{1}$ exists (or does not exist).

2. The equilibrium $E_{1}$ is always stable in $F, A, N, S$ and $C$ directions. Further, it is unstable (or stable) in $P$ direction whenever the equilibrium $E^{*}$ exists (or does not 
exist).

3. The equilibrium $E_{2}$ is stable in $F$ direction and unstable in $A$ direction. Further, it is stable in $N, P, S$ and $C$ directions iff conditions in (18) are satisfied, with $A_{i}=B_{i}$ for $i=1,2,3,4$.

4. The equilibrium $E^{*}$ is locally asymptotically stable iff

$$
A_{4}>0, A_{1} A_{2}-A_{3}>0, A_{3}\left(A_{1} A_{2}-A_{3}\right)-A_{1}^{2} A_{4}>0 .
$$

$A_{i}$ 's and $B_{i}$ 's are defined in Appendix.

Proof: Can be easily proved using simple stability analysis technique.

Theorem 2 The equilibrium $E^{*}$ is globally asymptotically stable inside the region of attraction $\Omega$, if the following conditions are satisfied:

$$
\begin{aligned}
& {\left[\frac{k_{1} Q / \alpha_{0}}{\left(k_{12}+Q / \alpha_{0}\right)\left(k_{12}+F^{*}\right)}\right]^{2} F^{*}<\frac{r \alpha_{0}}{\lambda_{1} L},} \\
& {\left[\frac{\beta_{1} \bar{q} / \delta_{m}}{\left(\beta_{12}+\bar{q} / \delta_{m}\right)\left(\beta_{12}+N^{*}\right)}\right]^{2} N^{*}<\frac{2 \alpha_{1} \beta_{10}}{3 \theta_{1}},} \\
& \frac{5 m_{2}\left[\pi \delta+\pi \delta_{1} C_{m}\right]^{2}}{\delta \alpha_{1}}<\min \left\{\frac{2 r \delta F^{*}}{5 \lambda_{1} L \eta^{2} \alpha^{\prime 2} Z^{2}}, \frac{4 m_{2} \delta \beta_{10} N^{*}}{15 \theta_{1}\left[\pi_{1} \alpha_{2}+\pi_{2} \beta_{10}\left(\bar{q} / \delta_{m}+P^{*}\right)\right]^{2}}\right\}, \\
& \frac{\delta_{1}^{2} S^{* 2}}{\alpha_{3}^{2}} \max \left\{\frac{4 m_{2} \pi^{2}}{\alpha_{1}}, \frac{m_{4}}{\delta}\right\}<\min \left\{\frac{m_{2} \beta_{10} N^{*}}{3 \theta_{1} \lambda_{11}^{2}}, \frac{m_{4} \delta^{2}}{5 \delta_{2}^{2} C^{* 2}}\right\},
\end{aligned}
$$

where $m_{2}$ and $m_{4}$ are defined in the proof.

Proof: Can be easily proved by considering the Lyapunov function

$$
\begin{aligned}
V=\frac{1}{2} & \left(F-F^{*}\right)^{2}+m_{1}\left(A-A^{*}-A^{*} \ln \frac{A}{A^{*}}\right)+\frac{m_{2}}{2}\left(N-N^{*}\right)^{2} \\
& +m_{3}\left(P-P^{*}-P^{*} \ln \frac{P}{P^{*}}\right)+\frac{m_{4}}{2}\left(S-S^{*}\right)^{2}+\frac{m_{5}}{2}\left(C-C^{*}\right)^{2},
\end{aligned}
$$

where $m_{1}, m_{2}, m_{3}, m_{4}$ and $m_{5}$ are positive constants to be chosen appropriately.

Since, it is difficult to identify the exact form of some of the equilibria, we check the existence of the equilibria by calculating them by using the parameter values given in Table 1. The model (1) shows the following four equilibria with positive coordinates, namely

$$
E_{0}=\left[\begin{array}{c}
5 \\
0 \\
50.6 \\
0 \\
0 \\
10
\end{array}\right], E_{1}=\left[\begin{array}{c}
3.95 \\
10.75 \\
40.27 \\
0 \\
0.22 \\
6.57
\end{array}\right], E_{2}=\left[\begin{array}{c}
5 \\
0 \\
0.09 \\
22.06 \\
0.84 \\
3.39
\end{array}\right], \quad E^{*}=\left[\begin{array}{c}
3.95 \\
10.75 \\
0.07 \\
19.62 \\
1.20 \\
2.62
\end{array}\right] .
$$


1. Point $E_{0}$, where there is no agricultural production in the system as well as there is no detritus and algae in the lake. As for the agricultural production free limit, this point should be unstable (it should not be possible to observe it).

2. Point $E_{1}$, where there is no algae in the lake, is stable.

3. Point $E_{2}$, where there is no agricultural production in the system. As we already discussed this equilibrium point must be unstable.

4. Finally, the point $E^{*}$, where all the six components exist in the system. This coexistence equilibrium is very common in nature, thus it should be stable in some ecosystems.

\section{Numerical simulation}

In this section, we check how different fertilizer input rates affect the system dynamics by considering the set of parameter values given in Table 1.

\subsection{System dynamics in the presence and absence of fertilizer}

First, to explore the role of fertilizer on the bloom formation by algae and its effects on the ecosystem, we compare the time evolution of all the variables in the absence $(Q=0 \mathrm{~kg} / \mathrm{ha} /$ day) and presence $(Q=2 \mathrm{~kg} / \mathrm{ha} /$ day $)$ of fertilizer input in the system (Fig. 1). Although, the use of fertilizer increases agricultural production $A$ (Fig. 1(b)), it also supplies a huge amount of nutrient $N$ (Fig. 1(c)) to the system, leading to the formation of a huge bloom of algae $P$ (Fig. 1(d)) which was not present in the absence of use of fertilizer. Consequently, high runoff from agricultural fields and mortality of algae increase the amount of detritus $S$ (Fig. 1(e)). Now, when the amount of detritus is low, the regeneration of nutrient from detritus needs very little DO and thus the DO level remains high. However, when the amount of detritus becomes high, initially the DO level in the water column increases due to the production from high algal biomass, but as time progresses decomposition of detritus becomes important which needs high amount of DO and the DO level depletes (Fig. 1(f)).

\subsection{System dynamics at different fertilizer input rates}

We also checked the equilibrium abundances of all the variables by continuously varying the fertilizer input concentration $(Q)$ in the system (Fig. 2). As the amount of the use of fertilizer increases, the fertilizer concentration increases almost linearly (Fig. 2(a)) whereas the agricultural production saturates (Fig. 2(b)) at high input rates. An increase in fertilizer input increases equilibrium nutrient concentration (Fig. $2(\mathrm{c})$ ) which results in a huge increase in algal biomass (Fig. 2(d)). High agricultural production and algal mortality increase the amount of detritus (Fig. 2(e)). Finally, regeneration of nutrient from detritus uses DO and keeps the DO level very low at high fertilizer input rate (Fig. 2(f)).

\subsection{Sensitivity analysis}

The model simulation demonstrates that high input of fertilizer $(Q)$ in the system results in an increase in algal biomass and decrease in the DO level. Now, to check 
how these variables are affected with variations in fertilizer input rate compared to other parameters, we perform a formal sensitivity analysis technique. In comparison with the effects of simply varying the parameters to look at the outcome of the model, the techniques of sensitivity analysis are mathematically more sophisticated. In the present case, we use a basic differential analysis approach. Use of this technique can be found in several other articles and text books [25-29].

The semi-relative sensitivity solutions with respect to some of the important parameters corresponding to the six state variables are computed. Here, the semi-relative sensitivity of the model solutions for a variable $X$ to a parameter $y$ is given by

$$
y \frac{\partial X(t, y)}{\partial y}
$$

and is computed by formally differentiating the ODE system (1) with respect to $y$ and interchanging the order of time and parameter derivative. Since we have 6 state variables, we get a system of 6 equations for the sensitivity functions $X_{y}(t, y)=$ $\frac{\partial X}{\partial y}(t, y):$

$$
\frac{d}{d t}\left(\frac{\partial X(t)}{\partial y}\right)=\frac{\partial f}{\partial X} \frac{\partial X(t)}{\partial y}+\frac{\partial f}{\partial y},
$$

with initial conditions $\frac{\partial X(0)}{\partial y}=0$. Here, $\frac{\partial f}{\partial X}$ represents the Jacobian of the ODE system (1) and $\frac{\partial f}{\partial y}$ is the derivative of the right side of system (1) (which is represented by $f(t, X, y))$ with respect to $y$. To get the sensitivity functions, first we solve system (23) for $X_{y}(t, y)$ by coupling it with the original system of ODE given in (1) (total 6+6 equations). The values of the sensitivity functions provide the rates of change of the variables with respect to the change in the chosen parameter $(y)$ as time progresses. For example, $P_{\beta_{1}}(50,0.067)=55$ means that the derivative of algal density $P(\mu \mathrm{gN} / \mathrm{L})$ with respect to the maximum nutrient uptake rate $\beta_{1}$ at time $t=50$ days and nutrient uptake rate $\beta_{1}=0.0671 /$ day is $55 \mu \mathrm{gN}$-days/L. Finally, the semi-relative sensitivity solutions are calculated by simply multiplying the unmodified sensitivity functions by the parameter $y$, i.e., $y X_{y}(t, y)$, which provides the amount the state will change when that parameter $y$ is doubled (i.e., a perturbation on the order of $y$ ). The semi-relative sensitivity solutions can be viewed as the Fréchet derivatives in the 'direction'of the corresponding parameter $y$ (see, [30]).

The sensitivities of algal density $(P)$ and DO level $(C)$ are plotted for six most sensitive relevant parameters $\left(Q, q, \gamma, \beta_{1}, \beta_{10}\right.$ and $\left.\delta_{2}\right)$ (Fig. 3). Among these parameters, $Q, q$ and $\beta_{10}$ can be influenced by human activities. From the graph, it is clear that the perturbations of the parameters exhibit their greatest influences early in the simulation, with a large initial expected variation in the algal density and DO level. Fig. 3(a) suggests that the doubling of $Q, q$ and $\gamma$ will yield sudden increase of algal biomass by time around $t=60$ days. On the other hand, $\beta_{1}$ results in a huge increase in algal biomass around day 50, followed by a sudden huge decrease just after few days. Such decrease in algal density is due to the decrease of nutrient availability (not shown in figure). In contrary, the doubling of $\beta_{10}$ results in the decrease in algal density. Doubling of all these parameters results in decrease in DO level (Fig. 3(b)). However, different parameters have different strength of influences; $\beta_{1}$ has its greatest influence on DO level, followed by $\delta_{2}, \gamma, Q, \beta_{10}$ and $q$, respectively.

Next, we look at the logarithmic sensitivity solutions

$$
\frac{\partial \log (X)}{\partial \log (y)}(t)=\frac{y}{X(t, y)} X_{y}(t, y)
$$


with respect to all of the previously mentioned parameters (Fig. 3(c), (d)). These quantities are dimensionless and indicate what percentage change of the variables can be expected from a doubling of a parameter $y$. Thus, to get a complete idea about the sensitivity of the solutions on a particular parameter, it is best to calculate both types of sensitivity solutions. Fig. 3(c) shows that the doubling of $\beta_{1}, \gamma, Q$ and $q$ results in $260 \%, 80 \%, 70 \%$ and $15 \%$ increase in algal density during the initial days, respectively, whereas $\beta_{10}$ results in $35 \%$ decrease. On the other hand, DO level decreases $280 \%, 150 \%, 130 \%, 120 \%, 50 \%$ and $25 \%$ due to the doubling of $\beta_{1}, \delta_{2}, \gamma$, $Q, \beta_{10}$ and $q$ respectively (Fig. $\left.3(\mathrm{~d})\right)$.

\section{Discussion}

Fertilizers enhance the growth of plants but its excess use can be detrimental to aquatic health. Scientists have long suspected that many algal blooms are fueled by fertilizer runoff from farming operations, which in many regions pour tons of excess nitrogen and other nutrients into rivers that eventually flow into lakes and coastal waters [31]. Using these excess nutrients, algae show a sudden population explosion that disrupt the aquatic ecosystems and even produce dead zones (low-oxygen zones) [32]. Apart from fertilizers, there are also other important human induced factors resulting in algal blooms. For example, eutrophication due to other sources than fertilizers [33] and overfishing [34]. In the present paper, we propose a mathematical model to comprehend the effect of fertilizers used in agriculture on the occurrence of algal blooms and compare the above mentioned three human induced activities on the occurrence of algal blooms and DO level.

HABs caused by hypoxic events (low-oxygen situations) are known as one of the most scientifically complex and economically damaging coastal issues worldwide that challenge our ability to protect the health of coastal ecosystems. In the last few decades, the number of hypoxic events has increased several folds [35]. During this event, the amount of DO becomes very low in the water column. DO is essential for many forms of life, including fish, invertebrates, aerobic bacteria and plants. These organisms need DO for respiration, similar to terrestrial organisms. Fish and crustaceans get the necessary oxygen for respiration through their gills, while aquatic plants and algae need dissolved oxygen for respiration in the absence of light. The amount of DO needed by different organisms is different. For example, bottom feeders, oysters, crabs and worms require minimal amounts of DO $(1-6 \mathrm{mg} / \mathrm{L})$, while the required amount of DO for shallow water fish is a little bit higher $(4-15 \mathrm{mg} / \mathrm{L})$. Normally, the DO content in a healthy aquatic system ranges from 6 to $13 \mathrm{mg} / \mathrm{L}$ [36]. However, when the level of DO goes below $2 \mathrm{mg} / \mathrm{L}$ which is necessary to sustain most animal life, the committee on environment and natural resources defined it as hypoxia [37]. Our study shows similar high DO level in the water column $(9.5 \mathrm{mg} / \mathrm{L})$ in the absence of the use of fertilizer. However, when fertilizer is used at high amounts in the agricultural field, algae start getting more nutrient from external sources due to agricultural runoff that results in a huge bloom of algae. When these algae die, the bacterial decomposition of the dead algal cells uses up very high amount of DO and leaves very little DO $(0.5 \mathrm{mg} / \mathrm{L})$ for organisms living in the aquatic system. This results in a typical hypoxic condition where organisms living in the water column start dying because of insufficient DO. In a report by Diaz et al. [38], currently there are more than 500 hypoxic systems covering over $240000 \mathrm{~km}^{2}$ around the globe related to human activities. These events also have economic impacts, including lost income for fisheries, lost recreational opportunities, decreased business in tourism industries, public health costs of illness, and expenses for monitoring and management [39]. 
In natural systems, algal blooms result from the combination of several factors. Thus to control algal blooms, it is important to know which factor is the most influential one. However, from the observation it is difficult to measure and identify the effects of different factors on bloom dynamics. At this point, mathematical model serves as an useful tool to solve this problem. In the present paper, we compare several factors including three human induced activities (fertilizer input in agricultural field, eutrophication of aquatic systems due to other sources than fertilizers, and overfishing) on the bloom dynamics and DO level by using a sophisticated sensitivity analysis technique. Our findings show that the increasing use of fertilizers in agricultural field causes more rapid algal blooms and decreases DO level much faster than eutrophication from other sources and overfishing. However, overfishing can also have large impact on the bloom development and DO level depletion [34]. Identification of the most responsible factor would help to determine the strategy for the policy makers to control algal blooms. It is to be noted that the outcome greatly depends on the parameterization of the system.

Occurrence of HABs can be controlled by regulating biological productivity in aquatic systems that happens due to the supply of nutrients to surface waters from agricultural fields. Reduction in external input of nutrients will help to reduce the occurrence and intensity of algal blooms. By using fertilizers sparingly, testing soil quality to measure the amount of fertilizer needed, by not using fertilizes before a rain storm, using organic fertilizers that release nutrients more slowly, etc., are some of the useful steps for the reduction of algal blooms in lakes. Thus, the most important challenge in the future is to integrate agriculture and aquaculture management in such a way that addresses the multiple needs of humans but also protects ecosystem services and functions that humans depend on.

Acknowledgements S. Chakraborty received support from HC Oersted postdoctoral fellowship programme in the form of a postdoctoral fellowship. P.K. Tiwari and S.K. Sasmal are thankful to National Board of Higher Mathematics, Department of Atomic Energy, Government of India for providing financial support in form of postdoctoral fellowship.

\section{Appendix}

$$
\begin{aligned}
& A_{1}=\alpha_{1}+\frac{\beta_{1} \beta_{12} P^{*}}{\left(\beta_{12}+N^{*}\right)^{2}}+\beta_{10} P^{*}+\delta+\delta_{1} C^{*}+\alpha_{3}+\delta_{2} S^{*}, \\
& A_{2}=\beta_{10} P^{*}\left(\alpha_{1}+\frac{\beta_{1} \beta_{12} P^{*}}{\left(\beta_{12}+N^{*}\right)^{2}}\right)+\frac{\theta_{1} \beta_{1} \beta_{12} P^{*}}{\left(\beta_{12}+N^{*}\right)^{2}} \frac{\beta_{1} N^{*}}{\beta_{12}+N^{*}} \\
& +\left(\delta+\delta_{1} C^{*}+\alpha_{3}+\delta_{2} S^{*}\right)\left(\alpha_{1}+\frac{\beta_{1} \beta_{12} P^{*}}{\left(\beta_{12}+N^{*}\right)^{2}}+\beta_{10} P^{*}\right) \\
& +\left(\delta+\delta_{1} C^{*}\right)\left(\alpha_{3}+\delta_{2} S^{*}\right)-\delta_{1} \delta_{2} S^{*} C^{*} \\
& A_{3}=\left\{\beta_{10} P^{*}\left(\alpha_{1}+\frac{\beta_{1} \beta_{12} P^{*}}{\left(\beta_{12}+N^{*}\right)^{2}}\right)+\frac{\theta_{1} \beta_{1} \beta_{12} P^{*}}{\left(\beta_{12}+N^{*}\right)^{2}} \frac{\beta_{1} N^{*}}{\beta_{12}+N^{*}}\right\} \\
& \left(\delta+\delta_{1} C^{*}+\alpha_{3}+\delta_{2} S^{*}\right)+\left\{\left(\delta+\delta_{1} C^{*}\right)\left(\alpha_{3}+\delta_{2} S^{*}\right)-\delta_{1} \delta_{2} S^{*} C^{*}\right\} \\
& \left(\alpha_{1}+\frac{\beta_{1} \beta_{12} P^{*}}{\left(\beta_{12}+N^{*}\right)^{2}}+\beta_{10} P^{*}\right) \\
& -\pi\left(\delta+\delta_{1} C^{*}\right)\left(\pi_{1} \alpha_{2}+2 \pi_{2} \beta_{10} P^{*}\right) \frac{\theta_{1} \beta_{1} \beta_{12} P^{*}}{\left(\beta_{12}+N^{*}\right)^{2}},
\end{aligned}
$$




$$
\begin{aligned}
A_{4}= & \left\{\beta_{10} P^{*}\left(\alpha_{1}+\frac{\beta_{1} \beta_{12} P^{*}}{\left(\beta_{12}+N^{*}\right)^{2}}\right)+\frac{\theta_{1} \beta_{1} \beta_{12} P^{*}}{\left(\beta_{12}+N^{*}\right)^{2}} \frac{\beta_{1} N^{*}}{\beta_{12}+N^{*}}\right\} \\
& \left\{\left(\delta+\delta_{1} C^{*}\right)\left(\alpha_{3}+\delta_{2} S^{*}\right)-\delta_{1} \delta_{2} S^{*} C^{*}\right\} \\
& -\pi\left(\delta+\delta_{1} C^{*}\right)\left(\pi_{1} \alpha_{2}+2 \pi_{2} \beta_{10} P^{*}\right)\left(\alpha_{3}+\delta_{2} S^{*}\right) \frac{\theta_{1} \beta_{1} \beta_{12} P^{*}}{\left(\beta_{12}+N^{*}\right)^{2}} \\
& +\lambda_{11} \delta_{1} S^{*} \pi\left(\delta+\delta_{1} C^{*}\right) \frac{\theta_{1} \beta_{1} \beta_{12} P^{*}}{\left(\beta_{12}+N^{*}\right)^{2}} .
\end{aligned}
$$

\section{References}

1. Y. Huang, R.L. Sass, W. Sun, W. Zhang, Y.Y. Sass, James A. Baker III Institute for Public Rice Production, (2010)

2. D.M. Anderson, J.M. Burkholder, W.P. Cochlan, P.M. Glibert, C.J. Gobler, C.A. Heil, R. Kudela, M.L. Parsons, J.E.J. Rensel, D.W. Townsend, V.L. Trainer, G.A. Vargo, Harmful Algae, 8(1), 39-53 (2008)

3. X. Gao, J.C. Ren, Z.X. Zong, Acta Scientiarum Naturalium, 30(4), 461-469 (1994)

4. D.J. Conley, Hydrobiologia, 410, 87-96 (1999)

5. P.J.S. Franks, Limnology and Oceanography, 42, 1273-1282 (1997)

6. D.W. Schindler, Can. J. Fish Aquat. Sci. 44(S1), (1987)

7. J. Sole, E. Garcia-Ladona, M. Estrada, J. Marine Systems, 62, 46-54 (2006)

8. J. Truscott, J. Brindley, Philosofical Transactions of the Royal Society of London, 347, 703-718 (1994)

9. J. Truscott, J. Brindley, Bull. Math. Biol. 56, 981-998 (1994)

10. J. Truscott, J. Plankton Res. 17, 2207-2232 (1995)

11. S. Chakraborty, S. Chatterjee, E. Venturino, J. Chattopadhyay, J. Bio. Phys. 33, 271-290 (2007)

12. R.D. Robarts, T. Zohary, New Zealand Journal of Marine and Freshwater Research, 21(3), 391-399 (1987)

13. S. Chakraborty, U. Feudel, Theor. Ecol. 7, 221-237 (2014)

14. H.W. Paerl, R.S. Fulton, P.H. Moisander, J. Dyble, Sci. World J. 1, 76-113 (2001)

15. D.W. Schindler, Limnol. Oceanogr. 51, 356-363 (2006)

16. A.K. Misra, Nonlinear Anal. Model. Control, 12(4), 511-524 (2007)

17. A.K. Misra, P. Chandra, V. Raghavendra, Adv. Water Res. 34, 1232-1238 (2011)

18. J.B. Shukla, A.K. Misra, P. Chandra, Nonlinear Anal. RWA. 9, 1851-1865 (2008)

19. A.K. Misra, P.K. Tiwari, E. Venturino, J. Biol. Phys. 42, 147-165 (2016)

20. P.A. Glibert, J.I. Allen, Y. Artioli, et al., Global Change Biology. 20, 3845-3858 (2014)

21. P.A. Soranno, S.L. Hubler, S.R. Carpenter, R.C. Lathrop, Ecological Applications. 6, 865-878 (1996)

22. J.E. Cloern, Mar. Ecol. Prog. Ser. 210, 223-253 (2001)

23. P.J.T.M.van Puijenbroek, J.H. Janse, J.M. Knoop, Ecol. Model. 174, 127-141 (2004)

24. H.I. Freedman, J.W.H. So, Math. Bio. 76, 69-86 (1985)

25. S. Chakraborty, S. Roy, J. Chattopadhyay, Ecol. Model. 213(2), 191-201 (2008)

26. M. Eslami, Theory of sensitivity in dynamic systems, Springer-Verlag, Heidelberg (1994)

27. M. Kleiber, H. Antunez, T.D. Hien, P. Kowalczyk, Parameter sensitivity in nonlinear mechanics: Theory and finite element computations, John Wiley \& Sons, New York (1997)

28. R.P. Dickinson, R.J. Gelinas, Journal of computational physics, 21, 123-143 (1976).

29. A. Varma, M. Morbidelli, H. Wu, Parametric Sensitivity in Chemical Systems, Cambridge University Press, Cambridge (1999).

30. H.T. Banks, D.M. Bortz, J. Math. Biol. 50, 607-625 (2005)

31. D.F. Boesch, D.M. Anderson, R.A. Horner, S.E. Shumway, P.A. Tester, T.E. Whitledge, NOAA Coastal Ocean Program, Decision Analysis Series, 10, (1997)

32. J.M. Beman, K.R. Arrigo, P.A. Matson, Nature, 434, 211-214 (2005) 

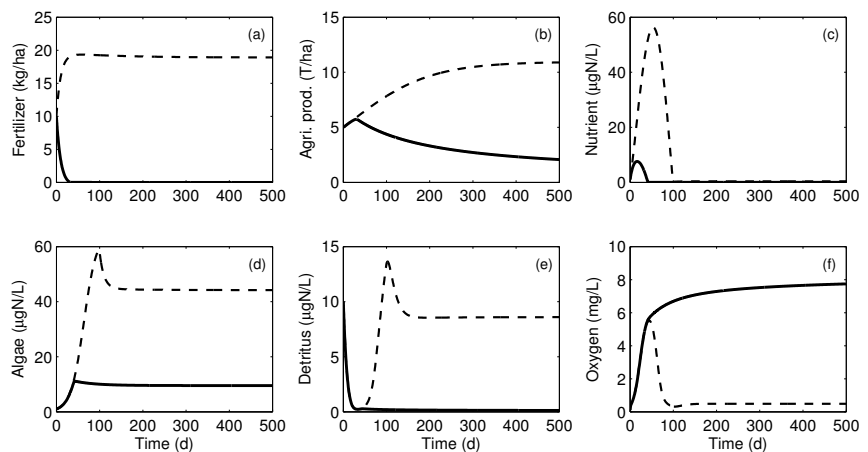

Fig. 1.

33. C.W.Y. Lam, K.C. Ho, Red tides in Tolo Harbour, Hong Kong. In: Red Tides: Biology, Environmental Science and Toxicology (Ed. by T. Okaichi, D.M. Anderson \& T. Nemoto), 49-52, Elsevier Science Publishing Co., New York (1989).

34. B.K. Eriksson, Does overfishing promote algal blooms? http://www.europarl.europa.eu/studies (2011)

35. R.Z. Diaz, R. Rosenberg, Science, 321, 926-929 (2008)

36. C. Kemker, Fondriest environmental, Inc. 19 Nov. http://www.fondriest.com/environmental-measurements/parameters/waterquality/dissolved-oxygen. (2013)

37. N.N. Rabalais, R.J. Diaz, L.A. Levin, R.E. Turner, D. Glibert, J. Zhang, Biogeosciences, 7, 585-619 (2010)

38. R. Diaz, N.N. Rabalais, D.L. Breitburg, https://www.oecd.org/tad/sustainableagriculture/49841630.pdf. (2012)

39. C.B. Lopez, Q. Dortch, E.B. Jewett, D. Garrison, Interagency working group on harmful algal blooms, hypoxia, and human health of the joint subcommittee on ocean science and technology, http://ocean.ceq.gov/about/sup_jsost_iwgs.html. (2008)

\section{Figure and table captions:}

Fig 1: Time series of (a) fertilizer $(F),(\mathrm{b})$ agricultural production $(A),(\mathrm{c})$ nutrient concentration $(N),(\mathrm{d})$ algal biomass $(P)$, (e) detritus $(S)$, and (f) DO level $(C)$ in the absence $(Q=0 \mathrm{~kg} / \mathrm{ha} /$ day; solid line $)$ and presence $(Q=2 \mathrm{~kg} / \mathrm{ha} /$ day; dashed line) of fertilizer input in the system.

Fig. 2: Equilibrium abundances of (a) fertilizer $(F)$, (b) agricultural production $(A),(\mathrm{c})$ nutrient concentration $(N),(\mathrm{d})$ algal biomass $(P),(\mathrm{e}) \operatorname{detritus}(S)$, and (f) DO level $(C)$ at different input concentrations of fertilizer $(Q \mathrm{~kg} / \mathrm{ha} /$ day $)$.

Fig. 3: Semi-relative sensitivity solutions of (a) algal density $(P)$ and (b) DO level $(C)$ with respect to $Q, q, \beta_{10}, \beta_{1}, \delta_{2}$ and $\gamma$. Logarithmic sensitivity solutions of $(\mathrm{c})$ algal density $(P)$ and $(\mathrm{d})$ DO level $(C)$ with respect to the same parameters. Here the initial conditions are chosen as $(10,5,1,1,10,0.1)$.

Table 1: Parameter values in the model system (1) 

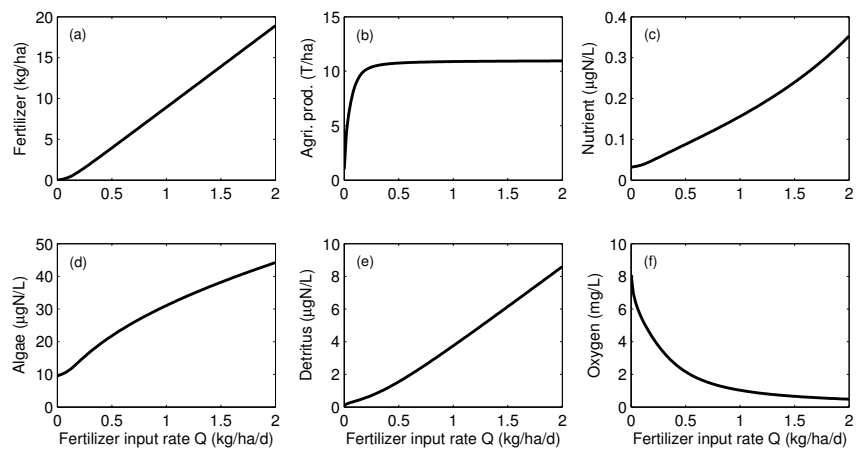

Fig. 2.
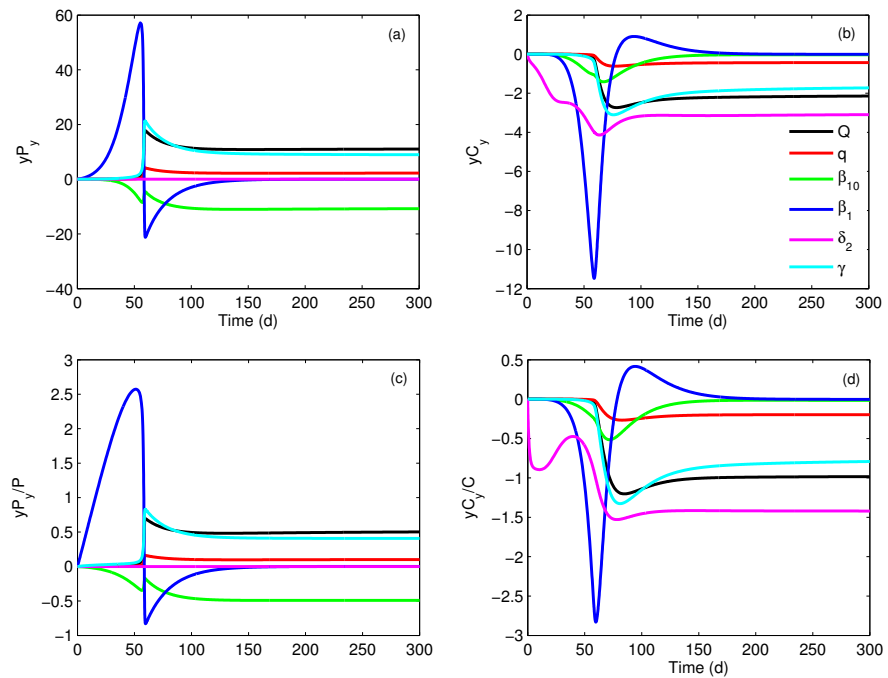

Fig. 3. 
Table 1.

\begin{tabular}{|c|c|c|c|}
\hline $\begin{array}{c}\text { Parameters/ } \\
\text { Variables }\end{array}$ & Descriptions & Units & Values \\
\hline$F$ & Concentration of fertilizer & $\mathrm{kg} / \mathrm{ha}$ & - \\
\hline$A$ & Density of agricultural production & ton/ha & - \\
\hline$N$ & Concentration of nutrients & $\mu \mathrm{gN} / \mathrm{L}$ & - \\
\hline$P$ & Density of algae & $\mu \mathrm{gN} / \mathrm{L}$ & - \\
\hline$S$ & Density of detritus & $\mu \mathrm{gN} / \mathrm{L}$ & - \\
\hline$C$ & Concentration of DO & $\mathrm{mg} / \mathrm{L}$ & - \\
\hline$Q$ & Rate of using fertilizers & $\mathrm{kg} / \mathrm{ha} /$ day & 0.5 \\
\hline$\alpha_{0}$ & Natural depletion rate of fertilizers & $1 /$ day & 0.1 \\
\hline$k_{1}$ & Maximum utilization rate of fertilizer & $\mathrm{kg} /$ ton/day & 0.01 \\
\hline$k_{12}$ & Half saturation constant & $\mathrm{kg} / \mathrm{ha}$ & 0.1 \\
\hline$\lambda_{1}$ & Conversion of fertilizer into agricultural production & ton $/ \mathrm{kg}$ & 1 \\
\hline$r$ & Intrinsic growth rate of agricultural production & $1 /$ day & 0.001 \\
\hline$L$ & Carrying capacity of agricultural production & ton/ha & 1 \\
\hline$q$ & Input rate of nutrients independent of agriculture & $\mu \mathrm{gN} / \mathrm{L} /$ day & 0.006 \\
\hline$\gamma$ & Input rate of nutrients through agricultural runoff & $1 / \mathrm{L} /$ day & 0.1 \\
\hline$\alpha$ & Nutrient content per unit of fertilizer & $\mu \mathrm{gN} / \mathrm{kg}$ & 1 \\
\hline$Z$ & Area of farmland & ha & 1 \\
\hline$\alpha_{1}$ & Natural depletion rate of nutrients & $1 /$ day & 0.01 \\
\hline$\beta_{1}$ & Maximum uptake rate of nutrients & $1 /$ day & 0.067 \\
\hline$\beta_{12}$ & Half saturation constant & $\mu \mathrm{gN} / \mathrm{L}$ & 0.17 \\
\hline$\theta_{1}$ & Conversion of nutrient into algae & - & 1 \\
\hline$\alpha_{2}$ & Natural death rate of algae & $1 /$ day & 0.001 \\
\hline$\beta_{10}$ & Algal mortality due to higher predation & $\mathrm{L} / \mu \mathrm{gN} /$ day & 0.001 \\
\hline$\eta$ & Growth rate of detritus due to crop residual & $1 / \mathrm{L} /$ day & 0.01 \\
\hline$\alpha^{\prime}$ & Nutrient content per unit of agricultural production & $\mu \mathrm{gN} /$ ton & 1 \\
\hline$\pi_{1}$ & Proportionality constant & 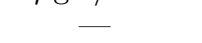 & 0.5 \\
\hline$\pi_{2}$ & Proportionality constant & - & 0.5 \\
\hline$\delta$ & Depletion rate of detritus in the absence of oxygen & $1 /$ day & 0.1 \\
\hline$\delta_{1}$ & Depletion rate of detritus in the presence of oxygen & $\mathrm{L} / \mathrm{mg} /$ day & 0.06 \\
\hline$\pi$ & Proportionality constant & - & 0.01 \\
\hline$q_{c}$ & Inflow rate of DO due to surface re-aeration & $\mathrm{mg} / \mathrm{L} /$ day & 0.5 \\
\hline$\alpha_{3}$ & Natural depletion rate of DO & $1 /$ day & 0.05 \\
\hline$\lambda_{11}$ & Inflow rate of DO by unit algal density & $\mathrm{mg} / \mu \mathrm{gN} /$ day & 0.0005 \\
\hline$\delta_{2}$ & Depletion rate of DO due to recycling of detritus & $\mathrm{L} / \mu \mathrm{gN} /$ day & 0.12 \\
\hline
\end{tabular}

